\title{
Testing the French Ad-Evoked Nostalgia Scale in a Nomological Network
}

\author{
Altaf Merchant, John B. Ford, Christian Dianoux, and Jean-Luc Hermann
}

\begin{abstract}
This study tests the French ad-evoked nostalgia scale in a nomological network of related constructs. Findings reveal significant differences in consumer reactions in France, as compared to earlier research based on American samples. Among the French, nostalgic advertising evokes personal memories and cultural nostalgia, contrasted to reports of past imagery and physiological and emotional reactions in the USA. Further, while cultural nostalgia is an important component of the French personal nostalgic experience, it is the personal memories that are the key to the creation of positive impressions about the ad and brand (brand heritage, brand bonds, and attitudes), as well as drive behavioral intentions.
\end{abstract}

\section{References available upon request.}

\author{
A. Merchant $(\bowtie)$ \\ University of Washington, Tacoma, Tacoma, WA 98402, USA \\ e-mail: altafm@uw.edu \\ J.B. Ford \\ Old Dominion University, Norfolk, VA 23529, USA \\ e-mail: jbford@odu.edu \\ C. Dianoux $\bullet$ J.-L. Hermann \\ University of Lorraine, 54000 Nancy, France \\ e-mail: christian.dianoux@univ-lorraine.fr; jean-luc.herrmann@univ-lorraine.fr
}

